\title{
Cadmium removal at high concentration in aqueous medium: mediated by Desulfovibrio alaskensis
}

\author{
P. A. López Pérez $\cdot$ R. Aguilar López • \\ M. I. Neria González
}

Received: 18 September 2012/Revised: 11 March 2014/Accepted: 21 April 2014/Published online: 15 May 2014

(C) Islamic Azad University (IAU) 2014

\begin{abstract}
Experimental studies were performed to evaluate the high capacity of cadmium removal by Desulfovibrio alaskensis strain $6 \mathrm{SR}$, which is a sulfate-reducing bacterium. The study was conducted in batch cultures of D. alaskensis $6 \mathrm{SR}$ in a medium with a high cadmium concentration. The results indicated that bacterial growth was not dramatically affected by the presence of $170 \mathrm{mg} / \mathrm{L}$ of cadmium, following a similar behavior to that of the control culture. Besides, we observed a fast production of extracellular polymeric substances, which play an important role in cadmium removal. The bacterium was able to remove $99.9 \%$ of cadmium at the tested concentration. The main mechanism of cadmium removal was its precipitation as cadmium sulfide (yellow precipitate), followed by its adsorption in the polymeric substances. Most cadmium up take occurred within the first $48 \mathrm{~h}$, and the largest cadmium adsorption capacity was achieved at $144 \mathrm{~h}$. Cadmium adsorption dynamics was evaluated by pseudo-first order and pseudo-second-order kinetic models; where the best adjustment was obtained with the pseudosecond-order model. The micrographs, obtained with transmission electron microscopy, showed a very low intracellular and periplasmic accumulation of cadmium in the cells. Thereby, this bacterium facilitates a process of
\end{abstract}

P. A. López Pérez · R. Aguilar López

Department of Biotechnology and Bioengineering,

CINVESTAV-IPN, Av. Instituto Politécnico Nacional 2508,

San Pedro Zacatenco, Mexico, DF 07360, Mexico

M. I. Neria González ( $₫)$

Chemical and Biochemical Engineering Division, Tecnológico

de Estudios Superiores de Ecatepec, Tecnológico, Valle de

Anáhuac, Ecatepec de Morelos 55210, Mexico

e-mail: ibineria@hotmail.com removal and recovery of cadmium at high concentrations without the need of cellular lysis or special washes.

Keywords Adsorption - Bioprecipitation - Cadmium ion . Sulfate reduction process

\section{Introduction}

Industrial activities produce large-scale environmental contamination with heavy metals, which are among the conservative pollutants that are neither subjected to bacterial attack, break down, nor degradation processes, and become permanent additions to the environment. Heavy metals have atomic weights between 63.5 and 200.6 (g/ $\mathrm{mol}$ ), and a specific gravity higher than $5 \mathrm{~g} / \mathrm{mL}$. They are classified into three main types: toxic metals such as mercury, lead, cadmium, and chromium; essential metals for living organisms such as copper, nickel, cobalt, and zinc; and radionuclides such as uranium (Das et al. 2008). Lead, cadmium, and mercury are examples of heavy metals that have been classified as priority pollutants by the U.S Environmental Protection Agency (U.S EPA) (Igwe and Abia 2006). The metals are toxic even at low levels of concentration and tend to accumulate over an extended period of time; as a result of this, their concentrations often exceed the permissible levels normally found in soil, water ways, and sediments. Their accumulation in the environment affects food chains and can profoundly disrupt biological processes, causing serious health problems in humans as well as ecological damage (Syasina et al. 2012). An example of this is cadmium, which is one of the most toxic metals and its presence in the environment affects any form of life (Igwe and Abia 2006). The most severe form of cadmium toxicity in humans is "itai-itai", a disease 
characterized by excruciating pain in the bones (Igwe and Abia 2006). Other health implications of cadmium in humans include kidney dysfunction, hepatic damage, and hypertension. For this reason, the removal of this pollutant from the environment, in particular wastewater, has received great attention.

Most of the heavy metal salts are soluble in water and form aqueous solutions and, consequently, cannot be separated by ordinary physical separation systems. Physicochemical methods, such as chemical precipitation, chemical oxidation or reduction, electrochemical treatment, evaporative recovery, filtration, ion exchange, and membrane technologies have been widely used to remove heavy metal ions from industrial wastewater (Igwe and Abia 2006; Das et al. 2008). These processes may be ineffective or expensive, especially when the heavy metal ions are in solutions, containing in the order of 1-100 mg dissolved heavy metal ions per liter (Das et al. 2008). Also, cation exchanger polyaniline $\mathrm{Sn}(\mathrm{IV})$ silicate has been synthesized to remove cadmium in diluted solution; however, it was studied by varying initial cadmium concentration (200-1,000 mg/L) and only was possible removal $92-80 \%$ of concentration of cadmium (Naushad et al. 2013). An alternative to the treatment of the metallic ions are biological methods that include microbial processes, although inorganic elements cannot be destroyed, microorganisms can change their speciation in such a way that their mobility and toxicity become markedly altered (Arjoon et al. 2013). Precipitation, volatilization, sorption, and solubilization are the reactions that alter the mobility of these inorganic elements. Besides, oxidation-reduction reactions mediated by microorganisms help in the conversion of a highly toxic, soluble, and mobile species into a species having much less toxicity and solubility, e.g., the biological reduction of $\mathrm{Cr}^{6+}$ to $\mathrm{Cr}^{3+}$, and the reduced form of many metals, including $\mathrm{Cu}, \mathrm{Zn}, \mathrm{Ni}, \mathrm{Cd}, \mathrm{As}$, $\mathrm{U}, \mathrm{Np}$, and Tc, form quite insoluble sulfide, hydroxide, or carbonate precipitates, and few species are more mobile in the reduced form (Arjoon et al. 2013). However, biosorption is the most employed technique for metal ions removal from waters. A variety of biomaterials are known to bind these pollutants, including bacteria, fungi, algae, and industrial and agricultural wastes (Aksu and Donmez 2006; Igwe and Abia 2006). The biosorption ability of biomass is due to the properties of the cell wall constituents, such as peptidoglycans, and the role of functional groups, such as carboxyl, amine, and phosphonate. Biosorption is a form of passive uptake of metallic ions (Igwe and Abia 2006; Das et al. 2008). Another biological treatment method is the selective precipitation of metals with biologically produced hydrogen sulfide $\left(\mathrm{H}_{2} \mathrm{~S}\right)$ by sulfate-reducing bacteria (SRB) (Jong and Parry 2003; Muyzer and Stams 2008). SRB are heterotrophic microorganisms that require strictly anaerobic conditions and a redox potential of $<-200 \mathrm{mV}$. Under anaerobic conditions, SRB oxidize simple organic compounds by using sulfate as a terminal electron acceptor, where the sulfate is reduced to sulfide (Muyzer and Stams 2008; Postgate 1981). The generation of sulfide produces reducing conditions, removal of acidity, and the precipitation of metals from the solution as sulfides. This property makes these bacteria suitable for the removal of acidity and metals from contaminated effluents (Muyzer and Stams 2008). The removal method consists of two stages: (1) the production of biogenic $\mathrm{H}_{2} \mathrm{~S}$ generated by sulfate-reducing bacteria during anaerobic respiration and (2) the reaction of biogenic $\mathrm{H}_{2} \mathrm{~S}$ with metallic ions, the reaction produces insoluble metal sulfides that can be easily separated from a solution (Jong and Parry 2003).

$\underset{\left(\mathrm{e}^{-} \text {donor }\right)}{\operatorname{Organic} \text { matter }}+\underset{\left(\mathrm{e}^{-} \text {acceptor }\right)}{\mathrm{SO}_{4}^{2-} \rightarrow 2} \mathrm{CH}_{3} \mathrm{COO}^{-}+\mathrm{HS}^{-}+\mathrm{HCO}_{3}^{-}$

$\mathrm{Me}^{2+}+\mathrm{HS}^{-} \rightarrow \mathrm{MeS} \downarrow$

The SRB secrete extracellular polymeric substances (EPS) to form biofilms as a protection mechanism against toxic agents, such as metals, that are located outside the bacterial cell surface and are constituted by polysaccharides, protein, nucleic acid, and phospholipids (Flemming and Wingender 2001). EPS can bind significant amounts of potentially toxic metals acting as material for biosorption. The electrostatic interactions between the metal ligands and negatively charged EPS outside the cell lead to the formation of stable complexes (Beech and Cheung 1995). The species of the genus Desulfovibrio are the most studied in this field, showing a high efficiency in the removal of different metallic ions in a range from a few milligrams per liter to as much as $100 \mathrm{mg} / \mathrm{L}$, for example, $\mathrm{Zn}$ (25-40 mg/L), Pb (75-80 mg/L), Cu (4-20 mg/L), Cd (>4-20 mg/L), Ni (10-20 mg/L), and $\mathrm{Cr} \quad(60 \mathrm{mg} / \mathrm{L})$ (Cabrera et al. 2006; Utgikar et al. 2002).

The purpose of this work is to describe and analyze the removal of a high cadmium concentration $(170 \mathrm{mg} / \mathrm{L})$ by a strain described as SRB, Desulfovibrio alaskensis, 6SR and to evaluate the removal mechanisms. This study was performed from January 2011 to March 2012, in the Environmental Biotechnology Laboratory of the Institute of Technology and Higher Education of Ecatepec, State of Mexico, Mexico.

\section{Materials and methods}

Organism, culture, maintenance, and purity test

The strain $D$. alaskensis 6SR was isolated from a biofilm developed inside an oil pipeline (Neria-González et al. 
2006). The optimal growing conditions for the bacterium were determinate as: temperature of $45^{\circ} \mathrm{C}, \mathrm{pH} 7.0$, and $30 \%(\mathrm{w} / \mathrm{v}) \mathrm{NaCl}$. The strain was maintained routinely in Hungate tubes with $5 \mathrm{~mL}$ of Postgate's medium C (Postgate 1981). To evaluate the organism's purity, decimal dilutions were performed in plates of anaerobic agar $\left(\mathrm{BBL}^{\circledR}\right)$ supplemented with $5 \mathrm{~g}$ sodium lactate $(60 \%$ w/w, SIGMA), $4.5 \mathrm{~g} \mathrm{NaSO}_{4}, 0.004 \mathrm{mg} \mathrm{FeSO}_{4}$, and $27.5 \mathrm{~g}$ $\mathrm{NaCl}$. The plates were placed in an anaerobic jar $\left(\mathrm{BBL}^{\mathrm{TM}}\right.$ $\mathrm{GasPak}^{\mathrm{TM}}$ Anaerobic Systems) and incubated at $37{ }^{\circ} \mathrm{C}$ until black colonies appeared. The presence of black colonies indicated the growth of SRB. One well-defined and isolated black colony was chosen and quickly transferred to $45 \mathrm{~mL}$ sterile Postgate's $\mathrm{C}$ medium in anaerobic conditions (Postgate 1981), and subcultures were made subsequently.

\section{Culture conditions}

Experiments with cadmium were carried out using modified Postgate's $\mathrm{C}$ medium, which contained $(\mathrm{g} / \mathrm{L}): \mathrm{KH}_{2} \mathrm{PO}_{4}$ (0.5), $\mathrm{NH}_{4} \mathrm{Cl}$ (1.0), $\mathrm{Na}_{2} \mathrm{SO}_{4}$ (4.5), $\mathrm{MgSO}_{4} \cdot 7 \mathrm{H}_{2} \mathrm{O}$ (0.06), sodium lactate (5.0), $\mathrm{CaCl}_{2} \cdot \mathrm{H}_{2} \mathrm{O}(0.06)$, yeast extract (1.0), sodium citrate $(0.3), \mathrm{NaCl}$ (30.0). This medium did not contain $\mathrm{Fe}^{2+}$ to allow evaluation of cadmium precipitation. The medium was adjusted to $\mathrm{pH} 7.0$ and $45 \mathrm{~mL}$ of medium was placed into $120 \mathrm{~mL}$ serum bottles. These vessels were capped with crimped aluminum butyl rubber stoppers and sterilized in an autoclave at $121^{\circ} \mathrm{C}$. Culture medium was prepared and dispensed in anaerobic conditions under a $\mathrm{N}_{2}$ (99.998\% purity) atmosphere. A stock cadmium acetate solution was prepared at $10,000 \mathrm{mg} / \mathrm{L}$ with respect to the ion $\mathrm{Cd}^{2+}$ and sterilized by membrane filtration (pore size, $0.22 \mu \mathrm{m}$ ). The reagents used in these experiments were analytical grade from SIGMA ${ }^{\circledR}$. Some bottles with medium were spiked with metal solution to obtain different concentrations of cadmium. All used reagents were analytical grade from SIGMA ${ }^{\circledR}$.

Minimal inhibitory concentration determination

Minimal inhibitory concentration (MIC) was determined in Postgate's C medium with concentrations of $50-300 \mathrm{mg} / \mathrm{L}$ of cadmium. Cultures were incubated at $37^{\circ} \mathrm{C}$ for a week, checking bacterial development by absorbance at $580 \mathrm{~nm}$ every $24 \mathrm{~h}$. MIC was estimated as the first dilution that completely inhibited bacterial growth in the Postgate's C medium.

\section{Cadmium removal}

The inoculum for the kinetic study was cultured in $250 \mathrm{~mL}$ of modified Postgate's $\mathrm{C}$ medium at $37{ }^{\circ} \mathrm{C}$ until an $\mathrm{OD}_{580}$ between 0.35 and 0.4 was obtained. A 5-mL aliquot of cell suspension was taken to inoculate $45 \mathrm{~mL}$ of fresh medium. All assays were conducted in two sets of 12 independent cultures in triplicate. A set of cultures was performed in the presence of $170 \mathrm{mg} / \mathrm{L} \mathrm{Cd}^{2+}$ and another in the absence of the metallic ion. The experiment lasted $216 \mathrm{~h}$. An independent culture was taken every $24 \mathrm{~h}$ for each set to determine biomass, sulfate, sulfide, lactate, acetate, and cadmium concentrations.

\section{Analytical methods}

A $0.5-\mathrm{mL}$ aliquot was taken anoxically via a syringe and immediately analyzed for the content of sulfide; sulfide levels were measured through a colorimetric assay (NeriaGonzález et al. 2006). A sodium sulfide solution, prepared under anoxic conditions, was used as standard.

Bacterial growth was followed through dry weight methodology. Using sterile syringes, 5-mL samples were taken and centrifuged at $15,600 \times g$ for $5 \mathrm{~min}$ (UNIVERSAL 320R, Hettich Zentrifugen, Germany); the remaining volume was reserved for the analysis of cadmium. The pellet was washed with $1 \%(w / v)$ EDTA buffer and dried at $70{ }^{\circ} \mathrm{C}$ for $24 \mathrm{~h}$ in an oven (ECOSHEL DOV23A), and the weight was registered. The supernatant was used to determine sulfate, lactate, and acetate. Sulfate consumption was measured by the turbidimetric method based on barium precipitation (Kolmert et al. 2000). Each measurement was done using a GENESYS 10 Uv Scanning Spectrophotometer (Thermo SCIENTIFIC). For lactate and acetate concentrations determination, a sample of $2 \mathrm{~mL}$ of supernatant was filtered through a $0.22-\mu \mathrm{m}$ pore-diameter filter and $1 \mathrm{~mL}$ of the filtrate was diluted 1:10 with a $10 \%$ $\mathrm{ZnCl}_{2}$ solution to remove sulfide. Then, the lactate and acetate concentrations were measured using an HPLC equipment (Shimadzu LC10Ai) connected to a UV detector $(\lambda=210 \mathrm{~nm})$ and a BioRad HPLC Organic Acid Analysis Column, using a flow rate of $0.700 \mathrm{~mL} / \mathrm{min}$ and a sulfuric acid/water (0.33/0.067) mobile phase. Lactic acid $(60 \%$ v/v, HPLC grade, SIGMA) and anhydride sodium acetate (HPLC grade, SIGMA ${ }^{\circledR}$ ) were used as standards.

\section{Analysis of cadmium}

The bottles with the culture were opened under aerobic conditions, and an approximately $40-\mathrm{mL}$ aliquot was centrifuged at $15,600 \times g$. The pellet was dried in an oven (ECOSHEL DOV23A) at $70{ }^{\circ} \mathrm{C}$ for $24 \mathrm{~h}$, and the weight was registered. The supernatant was recovered and filtered using a $0.22-\mu \mathrm{m}$ pore-diameter nitrocellulose membrane. The filtrate was collected in a new centrifuge tube, and the $\mathrm{pH}$ was measured. The dried pellet was suspended and digested with $1 \mathrm{~mL}$ of $\mathrm{HNO}_{3} / \mathrm{HClO}_{4}$ (5:2) at room 
temperature for $24 \mathrm{~h}$. The filtered liquid and digested samples were diluted in $2 \%(\mathrm{v} / \mathrm{v}) \mathrm{HNO}_{3}$ to determine cadmium content. Cadmium was assayed by atomic absorption spectrophotometry (AAS) (Atomic Absorption Spectrometer Spectr AA-20 plus, Varian) using a lamp exclusive for cadmium (HOLLOW CATHODE LAMP Element: Cadmium, Aurora Instruments).

The percentage of cadmium removal was calculated using the following equations:

$C \mathrm{~d}(\%)=\frac{\mathrm{C}_{0}-\mathrm{C}}{\mathrm{C}_{0}} \times 100$

where: $C \mathrm{~d}(\%)$ corresponds to percentage of cadmium removal, $C_{0}(\mathrm{mg} / \mathrm{L})$ is the initial cadmium concentration, and $C(\mathrm{mg} / \mathrm{L})$ is the cadmium concentration in solution at the end of the experiment.

Transmission electron microscopy (TEM) analysis

Bacterial cells grown for $72 \mathrm{~h}$ in Cd-supplemented $(170 \mathrm{mg} / \mathrm{L})$ modified Postgate's C medium were harvested by centrifugation and repetitively washed with saline phosphate buffer ( $\mathrm{pH} 7.2)$. The cells were fixed with an equal volume of glutaraldehyde $(2.5 \%)$ in the same buffer solution for $1 \mathrm{~h}$ at $4{ }^{\circ} \mathrm{C}$; the sample was washed three times with buffer solution and post-fixed with $1 \%$ osmium tetroxide. The cells were then gradually dehydrated with ethanol and finally embedded in pure resin. Thin sections were cut with a Dupont diamond knife in an LKB Ultramicrotome and dyed with lead acetate. Then, they were loaded onto a Formvar carbon-coated grid and observed with a transmission electron microscope (TEM, JEOL JEM 1010) at various magnifications.

Scanning electron microscopy (SEM) analysis

The biofilm structure with cadmium sulfide and the control culture were examined by scanning electron microscopy (SEM, JOEL JFM $5800 \mathrm{LV}$ ). The biofilm was fixed for $1 \mathrm{~h}$ in $2.5 \%$ glutaraldehyde, postfixed for $1 \mathrm{~h}$ with $1 \%$ osmium tetroxide, followed by dehydrating in a graded ethanol series. The samples were dried at critical point, and then coated with gold for SEM examination.

Extraction of extracellular polymeric substances and Fourier transform infrared (FT-IR) analysis

The EPS of the control culture were extracted by heat treatment and filtration. A bacterial culture bottle was opened and placed in water bath at $50{ }^{\circ} \mathrm{C}$ for $15 \mathrm{~min}$, the sample was vortexed twice; then, the cellular suspension was passed through a $0.45-\mu \mathrm{m}$ nylon membrane, the filtrate was collected in $250-\mathrm{mL}$ centrifuge bottles, and the EPS were then precipitated from it with an equal volume of cold ethanol overnight at $-20{ }^{\circ} \mathrm{C}$, followed by centrifugation at 2,500 $\times g$ for $10 \mathrm{~min}$ at $4{ }^{\circ} \mathrm{C}$ (UNIVERSAL 320R, Hettich Zentrifugen). The EPS pellet was transferred to a microcentrifuge tube and washed three times with $70 \%(\mathrm{v} / \mathrm{v})$ icecold ethanol; then, dried in an oven at $50{ }^{\circ} \mathrm{C}$ for $2 \mathrm{~h}$. The functional EPS groups were analyzed with a FT-IR spectrometer (Nicolet 6700 FT-IR).

\section{Results and discussion}

Effects of cadmium on growth and sulfate-reducing process

Minimum inhibitory concentration (MIC) was used to assay resistance of Desulfovibro alaskensis 6SR to cadmium at different concentrations, from 50 to $300 \mathrm{mg} / \mathrm{L}$. In general, D. alaskensis $6 \mathrm{SR}$ showed maximal resistance at $200 \mathrm{mg} / \mathrm{L} \mathrm{Cd}^{2+}$, and cadmium removal was evaluated at $170 \mathrm{mg} / \mathrm{L}$ (Fig. 1). Several authors have mentioned that the presence of cadmium affects bacterial growth in mixed or pure SRB cultures (Cabrera et al. 2006; Utgikar et al. 2002), because high concentrations of heavy metals block essential functional groups or modify the active conformations of biological molecules ( $\mathrm{Li}$ et al. 2004). The lag phase can increase up to 4 days with increasing cadmium concentrations in solution; besides, cadmium decreases the sulfate reduction process affecting bacterial growth (Cabrera et al. 2006; Naz et al. 2005). However, in this work, growth of $D$. alaskensis $6 \mathrm{SR}$ was not affected markedly in the presence of $170 \mathrm{mg} / \mathrm{L}$ cadmium. During 9 days, bacterial growth was monitored and one sample for each set of cultures was taken every $24 \mathrm{~h}$ to quantify biomass, lactate,

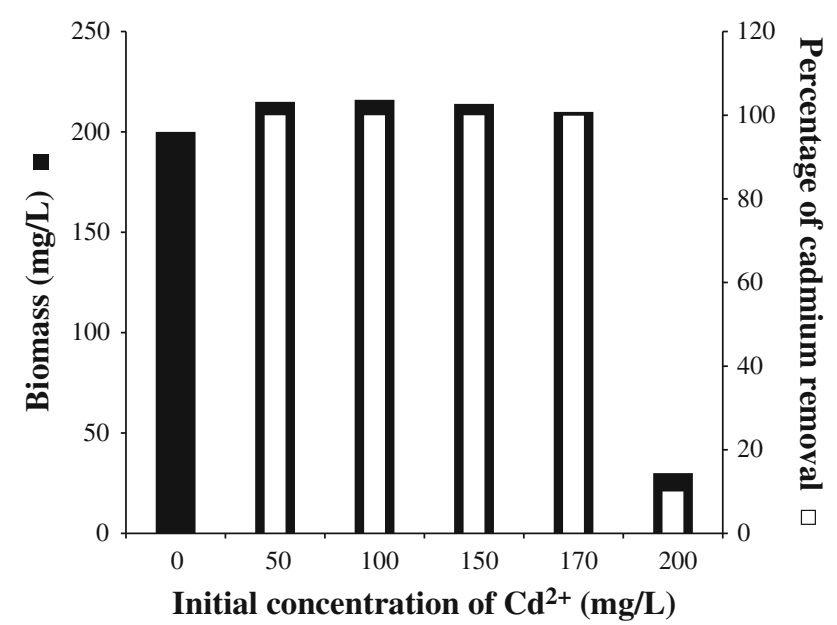

Fig. 1 Minimal inhibitory concentration determination. Growth of Desulfovibrio alaskensis 6SR in different concentrations of cadmium, expressed by dry weight 

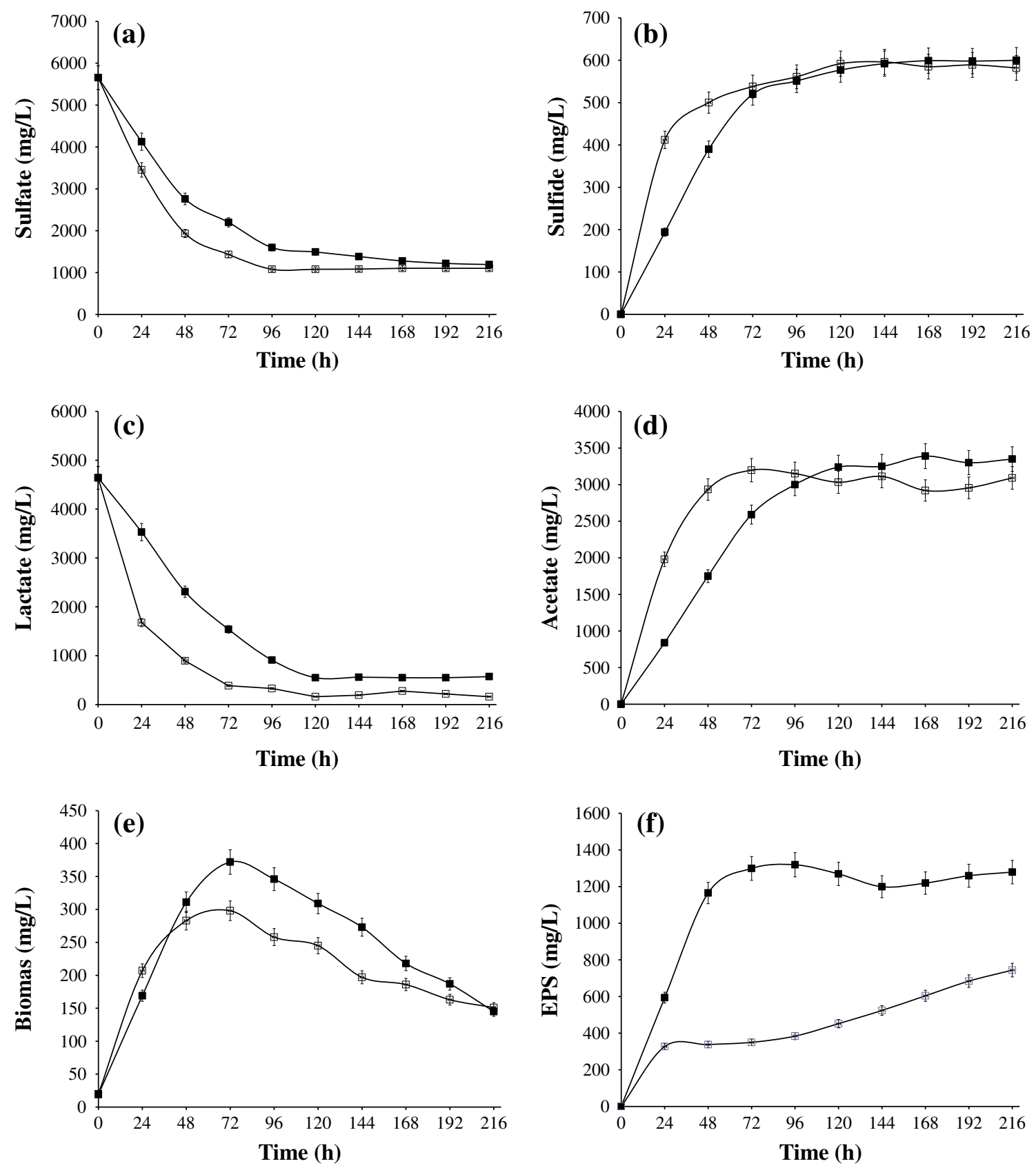

Fig. 2 Evolution of Desulfovibrio alaskensis 6SR in the presence of cadmium $(170 \mathrm{mg} / \mathrm{L})$. a Consumption of sulfate, b Production of sulfide, c Consumption of lactate, d Production of acetate,

sulfate, acetate, sulfide, and metal concentration. Results of bacterial growth in the presence of the cadmium ion with respect to the control are depicted in Fig. 2. The concentration of dry biomass in the presence of cadmium was $370 \mathrm{mg} / \mathrm{L}$, whereas, in the control culture, it was $285 \mathrm{mg} / \mathrm{L}$, Fig. 2a. The sulfate-reducing activity was affected slightly by the high cadmium concentration, as observed in Fig. 2b. After 120 h (5 days) of incubation, most of the lactate added to the medium was oxidized to acetate and approximately $77 \%$ sulfate was consumed,

e Production of biomass, $\mathbf{f}$ Evolution of EPS. Full squares (filled square) indicate growth with cadmium and empty squares (open square) indicate growth without cadmium

maximal production of hydrogen sulfide was approximately $600 \mathrm{mg} / \mathrm{L}$ in both cultures (see Fig. 2c, d). Regarding biomass concentration, this was larger than that of the control culture after $48 \mathrm{~h}$ (Fig. 2e); but this may have been produced by cellular biosorption of the metal. In general, it is accepted that a high cadmium concentration in solution induces a decrease in the sulfate reduction rate and affects the precipitation of the metal; however, this was not observed with $D$. alaskensis $6 \mathrm{SR}$. This finding can be attributed to the fact that cultures were started with young 
cells at their maximal reproductive rate; in addition, these cells were not washed, as done in other studies (Cabrera et al. 2006; Klonowska et al. 2008). In complementary experiments performed for this work, it was observed that, when harvesting and washing the cells, the sulfide was removed as reported (Klonowska et al. 2008). However, cells lost viability; even when taking the precautions needed for this kind of bacterium, hence, bacterial growth was affected by cadmium. Therefore, we omitted the harvesting and cellular washing for this work. Another important characteristic observed during cellular growth was the immediate EPS production in cultures exposed to cadmium with respect to the control culture (Fig. 2f). The figure shows a fast EPS production in the presence of cadmium, this can be attributed to the action of EPS as a protection mechanism of the cells against toxic substances (e.g., heavy metals, $\mathrm{H}_{2} \mathrm{~S}$ ), also EPS production is unequivocally accepted as a key mechanism facilitating cell attachment and promoting the development of a biofilm (Quintelas et al. 2009). Following this idea, the high cadmium concentration in the medium provoked a stress condition that induced the bacterium to produce EPS to form a protective barrier. In the control cultures, production of EPS was observed during the stationary phase, where $\mathrm{H}_{2} \mathrm{~S}$ reached its maximum production $(\sim 600 \mathrm{mg} / \mathrm{L}), \mathrm{H}_{2} \mathrm{~S}$ accumulation causes a toxic effect on the cells (Caffrey and Voordouw 2009), despite the sulfate-reducing nature of the bacterium.

\section{Removal of cadmium}

Based on the obtained experimental results, Desulfovibrio alaskensis $6 \mathrm{SR}$ could be a bacterium with a great potential for the removal of high cadmium concentrations $(\geq 170 \mathrm{mg} / \mathrm{L})$ as compared with physicochemical systems and other microorganisms, including species of the same genus (Arakaki et al. 2002; Cunningham and Lundie 1993; Naz et al. 2005). Although D. alaskesis 6SR is an anaerobic bacterium, which could be a drawback for its cultivation and manipulation, this presents a great advantage in the sense that an anaerobic culture produces scarce biomass and its simple mechanism of removal allows for an easy recovery of cadmium sulfide. D. alaskensis 6 SR was able to remove $99.9 \%$ of the cadmium at the tested concentration $(170 \mathrm{mg} / \mathrm{L})$. The concentration of cadmium in the liquid phase and biofilm (considering as biofilm a blend of the biomass and EPS) is presented in Fig. 3. Cadmium concentration in the liquid phase was $<1 \mathrm{mg} / \mathrm{L}$ after $120 \mathrm{~h}$, whereas, in the biofilm, cadmium sulfide was retained, taking a yellowish coloration and cadmium concentration was $144 \mathrm{mg} / \mathrm{L}$; in the free biomass, it was barely detected $(0.8 \mathrm{mg} / \mathrm{L})$.

The kinetics of the adsorption capacity ( $q=$ milligrams of metal sorbed per gram of sorbent) is shown in Fig. 4, where metal concentration data versus time are plotted.

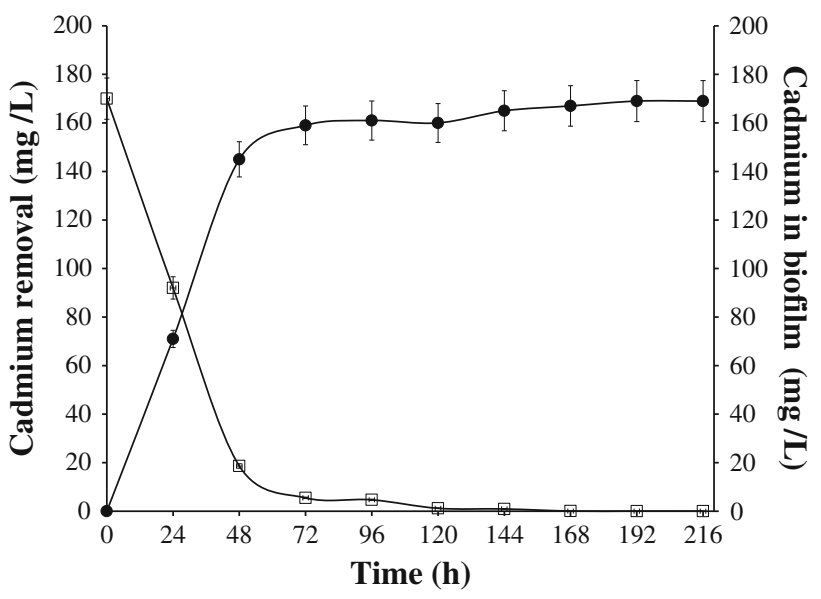

Fig. 3 Cadmium removal by Desulfovibrio alaskensis 6SR. Symbols: (open square) Concentration of cadmium in the liquid phase and (filled circle) concentration of cadmium adsorbed on the biofilm

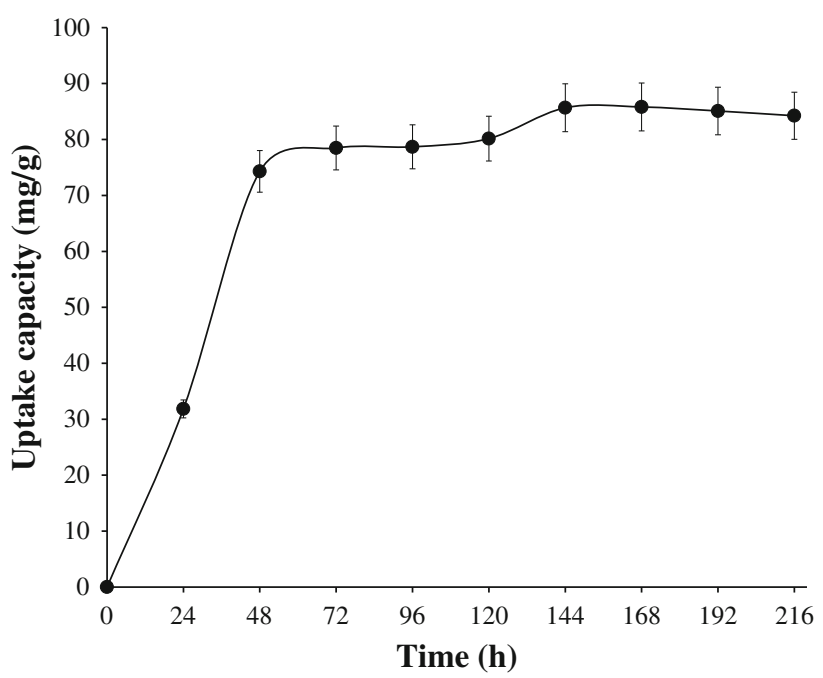

Fig. 4 Effect of contact time on biosorption of $\mathrm{Cd}^{2+}(170 \mathrm{mg} / \mathrm{L})$ by Desulfovibrio alaskensis 6SR

Most of the cadmium uptake occurred within the first $48 \mathrm{~h}$, with a further small adsorption over the next $96 \mathrm{~h}$. A similar influence of the metal-to-adsorbent ratio on reaction kinetics has been reported elsewhere ( $\mathrm{Li}$ et al. 2004). The largest adsorption capacity was achieved at $144 \mathrm{~h}$ (Fig. 4). Moreover, experimental adsorption rate was analyzed by proposing pseudo-first -order and pseudo-second-order kinetic models, concluding that the best adjustment was obtained with the pseudo-second-order model (Eq 4) as follows:

$\frac{\mathrm{d} q}{\mathrm{~d} t}=k\left(q_{\mathrm{e}}-q\right)^{2}$

The following parameters were calculated employing a Levenberg-Marquardt optimization method for two kinetic models, generating the following parameter set: 
Pseudo-first order $\left.k=0.04(\mathrm{~g} / \mathrm{mg} \mathrm{h}), q_{\mathrm{e} \text { (calculated }}\right)=6$ $(\mathrm{mg} / \mathrm{g}), q_{\mathrm{e}}$ (experimental $)=13.8(\mathrm{mg} / \mathrm{g}), r^{2}=0.88$.

Pseudo-second order $\left.k=0.016(\mathrm{~g} / \mathrm{mg} \mathrm{h}), q_{\mathrm{e} \text { (calculated }}\right)=$ $0.022(\mathrm{mg} / \mathrm{g}), \quad q_{\mathrm{e}}$ (experimental) $=13.8(\mathrm{mg} / \mathrm{g}), r^{2}=0.98$, $q_{\text {e(calculated) }}=13(\mathrm{mg} / \mathrm{g})$. This suggests that the sorption of cadmium by $D$. alaskensis $6 \mathrm{SR}$ follows a second-order kinetics.

The capacity to remove cadmium $(170 \mathrm{mg} / \mathrm{L})$ through a sulfate-reducing culture of $D$. alaskensis 6SR exceeds the removal capacity of SRB previously reported, including other species (Quintelas et al. 2009, Zamani et al. 2013). Specifically, SRB can remove cadmium between 10 and $100 \mathrm{mg} / \mathrm{L}$ with a removal efficiency of 93 to $98 \%$; for example, a mixed culture of SRB obtained from activated sludge removed $99.9 \%$ of cadmium corresponding to an initial concentration of $20 \mathrm{mg} / \mathrm{L}$, and a pure culture of D. magneticus precipitates more than $95 \%$ of cadmium at a concentration of $1.3 \mathrm{mg} / \mathrm{L}$ in the growth medium (Arakaki et al. 2002). Other microorganisms, such as Azomonas agilis PY101, removed approximately $90 \%$ of cadmium in an artificial wastewater containing $1 \mathrm{mM} \mathrm{CdCl}_{2}$
$(112 \mathrm{mg} / \mathrm{L})$, these microorganisms have the capacity to accumulate cadmium from $2.37 \mathrm{mM}(266.4 \mathrm{mg} / \mathrm{L})$ to $6.28 \mathrm{mM}(705.8 \mathrm{mg} / \mathrm{L})$ per gram of dry weight of cells; in addition, they can precipitate the cadmium by organic sulfide-production under aerobic conditions (You and Park 1998). Similarly, Pseudomonas aeruginosa is capable of removing $>99 \%$ of up to $5 \mathrm{mM}(562 \mathrm{mg} / \mathrm{L})$ of cadmium in $140 \mathrm{~h}$ under an alkaline condition, which favored the precipitation of hydroxides (Wang et al. 1997). In general, the reported concentrations of cadmium removal by SRB do not surpass $100 \mathrm{mg} / \mathrm{L}$, while $D$. alaskensis 6SR has the ability to tolerate and remove a large cadmium amount, as discussed previously, see Fig. 1.

Sulfate-reducing bacteria (SRB) can remove cadmium as insoluble metal sulfide precipitate, but can exhibit other mechanisms of metal removal, like precipitation by special particles; for example, magnetic particles that generate precipitation of cadmium on the cellular surface in Desulfovibrio magneticus strain RS-1 (Arakaki et al. 2002). Metallic accumulation at the cellular level is another mechanism due to the expression of metallothioneins,
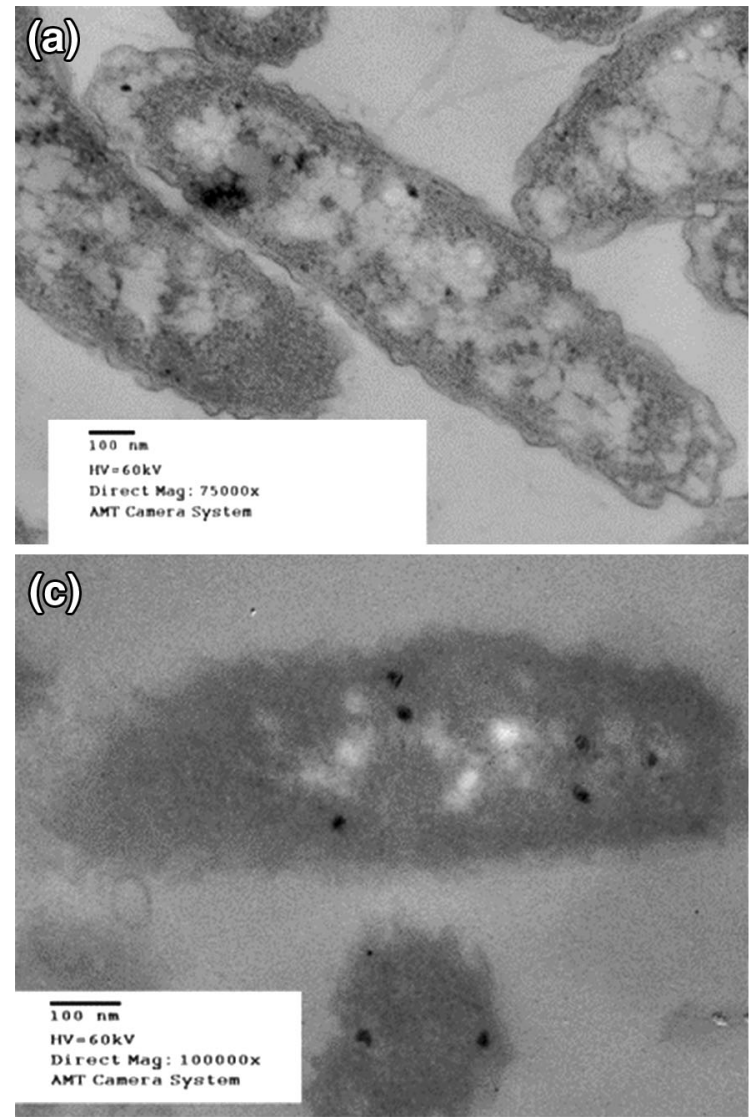

Fig. 5 Transmission electron micrographs of Desulfovibrio alaskensis 6SR (a) Cells of $D$. alaskensis 6SR stained with lead acetate, $\mathbf{b} D$. alaskensis $6 \mathrm{SR}$ grown in the presence of $170 \mathrm{mg} / \mathrm{L}$ cadmium $(72 \mathrm{~h}$
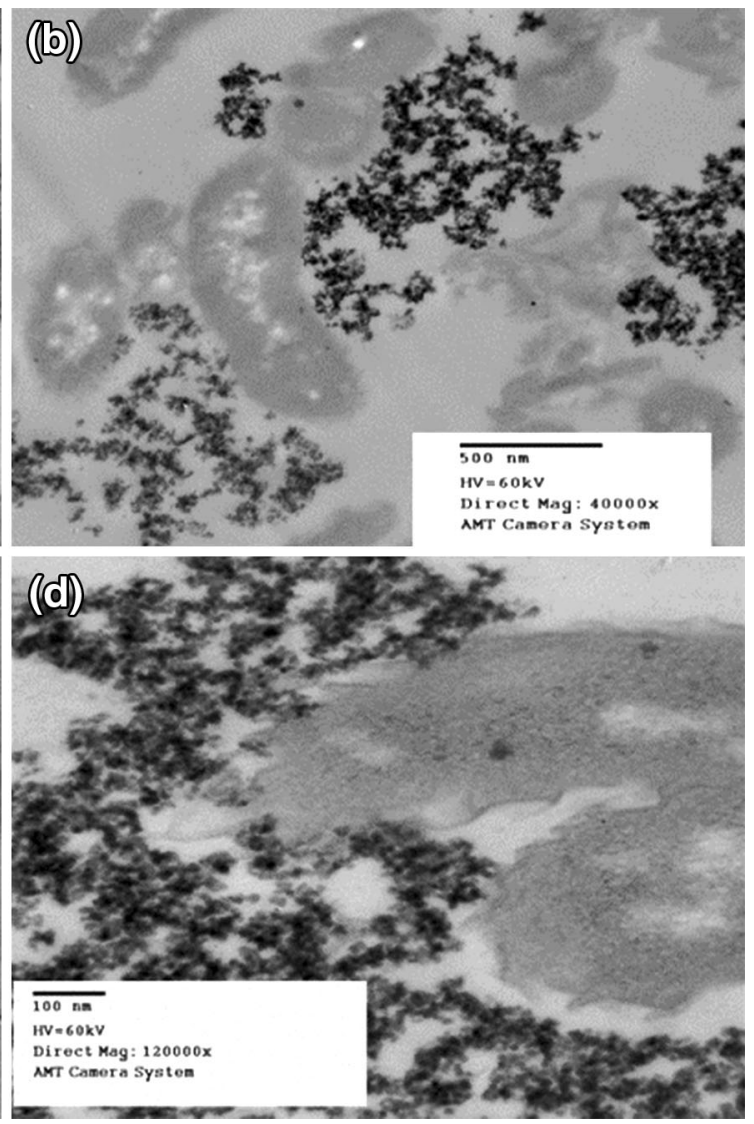

incubation), $\mathbf{c}$ an unstained micrograph shows the low intracellular and periplasmic accumulation of cadmium, d cadmium sulfide precipitated after $96 \mathrm{~h}$ 
Fig. 6 Growth of Desulfovibrio alaskensis $6 \mathrm{SR}$ in a medium with a high cadmium concentration $(170 \mathrm{mg} / \mathrm{L})$. Pictures show biofilm with the precipitated cadmium sulfide and the control culture

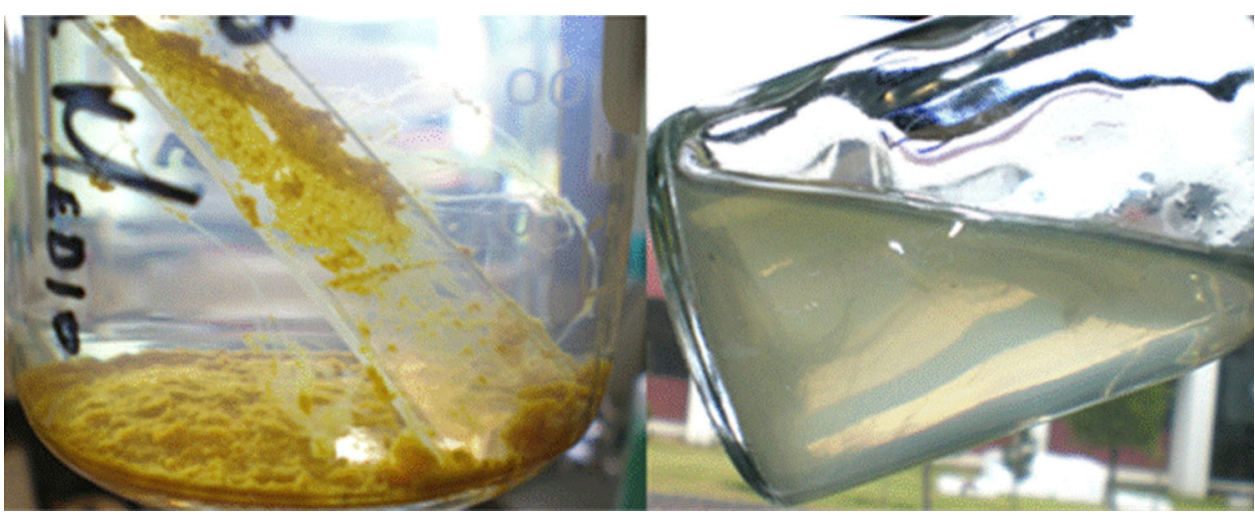

metal binding proteins that maintain metal ion homeostasis and detoxification in bacteria ( $\mathrm{Naz}$ et al. 2005; Odermatt et al. 1993). Additionally, cadmium transport in SRB is associated to the $\mathrm{Mn}^{2+}$ transport system (Perry and Silver 1982). In addition, a high metal concentration may lead to intracellular precipitation of the metal. The use of unstained samples for TEM has been reported to indicate the accumulation of metal in the cell (Naz et al. 2005). This methodology was used to indicate the accumulation of metal in cells of Desulfovibrio desulfuricans DSM 1926 and Desulfococcus multivorans DSM 2059 (Naz et al. $2005)$, both strains showed an accumulation of cadmium in the intracellular and periplasmic space, when grown in the presence of $0.5 \mathrm{mM}$ cadmium $(\sim 56 \mathrm{mg} / \mathrm{L})$. However, these mechanisms were not followed by $D$. alaskensis $6 \mathrm{SR}$, a TEM analysis was used to evaluate the accumulation of cadmium in the cells. The micrographs obtained from D. alaskensis $6 \mathrm{SR}$ were not stained when cadmium was present, whereas cells not exposed to the metal were stained with lead citrate. Comparison of both micrographs showed a very low intracellular and periplasmic accumulation of cadmium in the cell, see Fig. 5a-c, but an accumulation of cadmium was observed in the intercellular space, see Fig. 5d. Therefore, the main mechanism was the precipitation of cadmium sulfide (yellow precipitate), followed by its accumulation in the biofilm, considering that biofilm is formed by the cell attached to EPS (see Fig. 6). The yellow coloration of the biofilm was a powerful indicator of cadmium sulfide adsorbed. This fact was analyzed by SEM, the micrographs showed a great accumulation of cadmium in the biofilm and it present a different structure in contrast to the control biofilm (see Fig. 7). In the control culture, the bacterial cells adhered to the EPS was observed, whereas, in the biofilm developed with cadmium, only amorphous material was seen. The EPS plays a very important role in the development of biofilm, but also in the sorption of heavy metals. EPS contain ionizable functional groups such as carboxyl, phosphoric, amine, and hydroxyl groups, which enable EPS to sequester heavy metals. The presence of these functional groups on the EPS produced by strain 6SR was determined by FT-IR analysis. Figure 8 shows the FT-IR spectra of EPS without cadmium. Analysis of the FT-IR spectrum of EPS demonstrated the presence of intensive bands, corresponding to $-\mathrm{C}-\mathrm{O}-\mathrm{C}-, \mathrm{P}-\mathrm{O}-\mathrm{C}, \mathrm{COO}-, \mathrm{P}=\mathrm{O},-\mathrm{NH}_{2},-\mathrm{C}-\mathrm{N}-,-\mathrm{OH}$, and others (Ojeda et al. 2008; Quintelas et al. 2009; Zhang et al. 2006). The different functional groups observed in the EPS agree well with the results of other authors (Zhang et al. 2006). These functional groups can correspond to proteins, polysaccharides, while the presence of $\mathrm{CH}$ (weaker bands) and carboxylic groups indicate the presence of lipids whose content is usually too low to be detected with IR spectra (Beech and Cheung 1995; Quintelas et al. 2009). In addition, the $\mathrm{CH}$ group of lipids, the carboxyl group, and the $-\mathrm{OH}$ group of proteins and polysaccharides have been reported to be involved in cadmium binding. Though, the medium's $\mathrm{pH}$ plays an important role by inducing deprotonation of functional EPS groups and generating negatively charged sites on the surface of the EPS (biosorbent), which increases the biosorption of the positively charged $\mathrm{Cd}^{2+}$ ions through electrostatic forces of attraction. This fact has been also observed in Pseudomonas aeruginosa when it is used for cadmium removal, the $\mathrm{pH}$ of the culture medium is adjusted to 9.1 to induce deprotonation of functional groups of the cellular wall, and then the cadmium ions are precipitated as hydroxides on the cell wall (Wang et al. 1997). However, in the sulfate-reducing system with cadmium the initial $\mathrm{pH}$ was 6.7 and of 7.5 at the end of the experiment; this behavior was a natural response of the system, just as observed in other similar systems and in SRB consortia (Braissant et al. 2007). Thus, considering that the biofilm of $D$. alskensis 6SR is formed by EPS attached to cells, then the slight alkalinity of the medium (pH 7.5) supports the deprotonation of functional groups of EPS, and the surface of the biofilm becomes negatively charged inducing biosortion of the cadmium ion. We 
Fig. 7 Scanning electron micrographs of the biofilm structure. The upper micrograph shows the biofilm with the precipitated cadmium sulfide. The lower micrograph shows the control biofilm, in which bacterial specimens can be observed
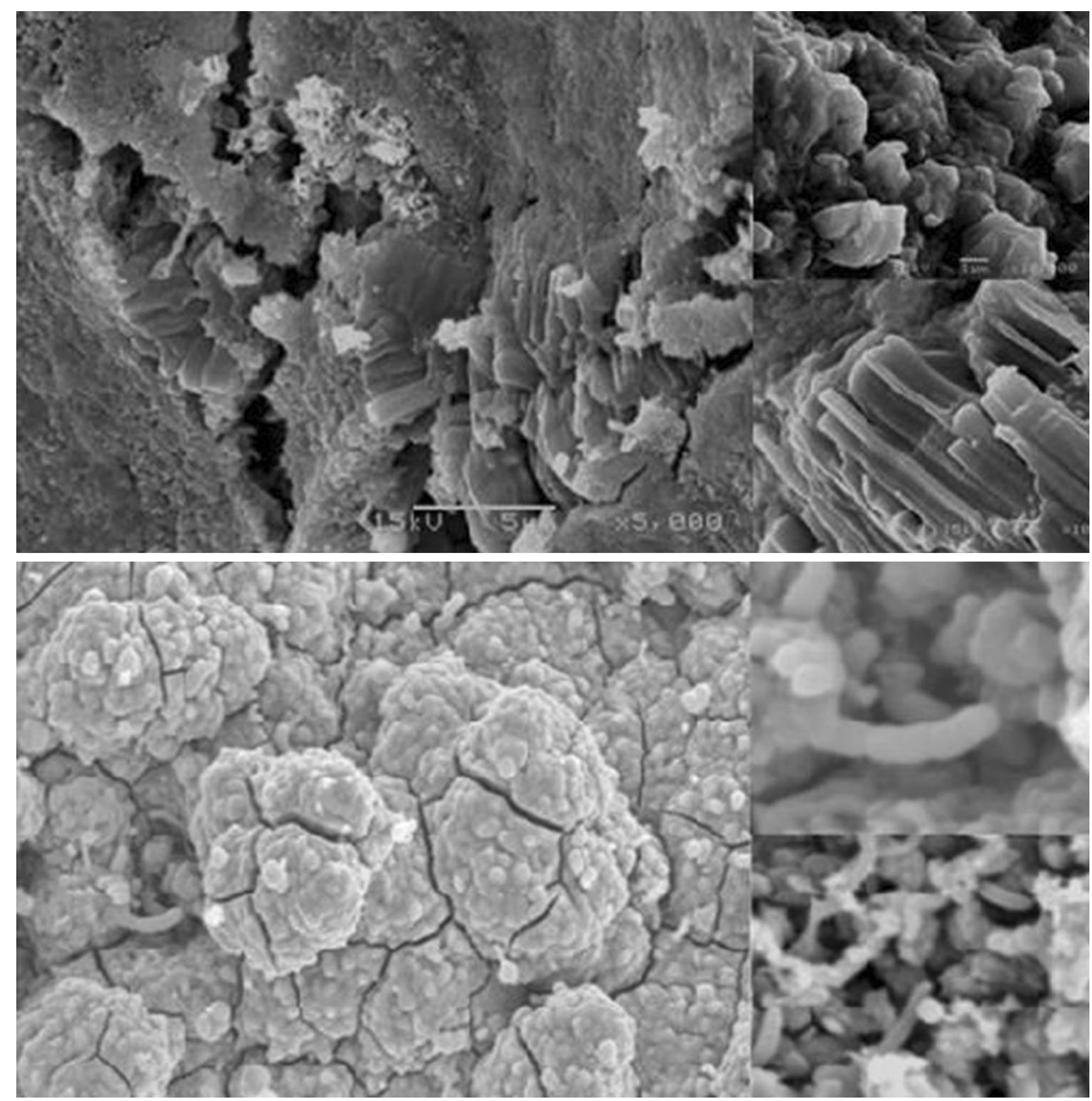

assume that the high concentration and toxicity of cadmium provoke a rapid production of EPS with respect to the control culture, developing a protective barrier, biofilm, which leads to a low intracellular accumulation. Therefore, the hydrogen sulfide is precipitated and accumulated on the biofilm.

\section{Biotechnological potential of Desulfovibrio alaskensis 6SR}

Desulfovibrio alaskensis 6SR is proposed as a bacterium with a great potential for the removal of high cadmium concentrations ( $\geq 170 \mathrm{mg} / \mathrm{L})$ compared to physicochemical systems and other microorganisms, including species of the same genus, such as Desulfovibrio sp. (20 mg/L), D. vulgaris $(11 \mathrm{mg} / \mathrm{L})$, D. magneticus $(1.3 \mathrm{mg} / \mathrm{L})$, D. desulfuricans (56 mg/L) (Arakaki et al. 2002; Naz et al. 2005). Although, D. alaskesis 6SR is an anaerobic bacterium that could be a drawback for its cultivation and manipulation, this presents a great advantage in the sense that an anaerobic culture produces scarce biomass and its simple mechanism of removal allows an easy recovery of cadmium sulfide, which has an added value, e. g., in the manufacture of solar cells (Pan et al. 1997). On the other hand, microalgae are considered as excellent biosorption agents due to their great surface extension and their ability to remove concentrations $>200 \mathrm{mg} / \mathrm{L}$ of cadmium, and other microalgae can accumulate intracellularly this metal (Aksu and Donmez 2006; Igwe and Abia 2006), in both cases a large amount of biomass is required as well as special growth conditions. Other microorganisms, such as fungi and aerobic bacteria, can remove cadmium due to their biosorption capacity, which depends on the species and growth conditions (Das et al. 2008). Besides in the adsorption process, the recovery of cadmium is expensive, because treatments of washing with special buffers and $\mathrm{pH}$ change are required; in bioaccumulation process, the cellular lysis and a combination of separation methods are needed; in consequence, the biomass is burned and confined in special places. Some facultative aerobic bacteria have been genetically manipulated for the removal of cadmium. The thiosulfate reductase gene ( $p h s A B C)$ from 


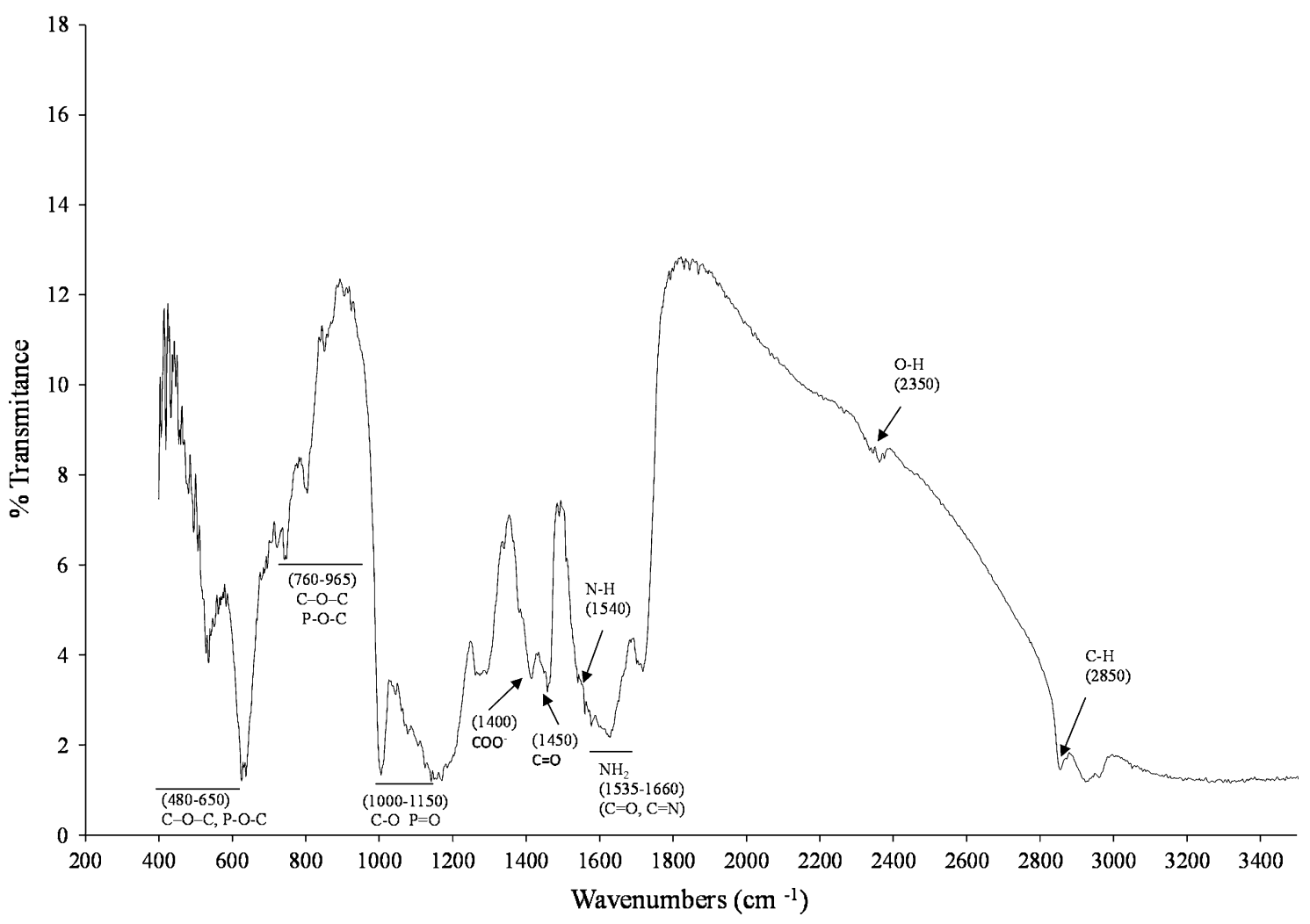

Fig. 8 FT-IR spectra of EPS obtained from control culture of Desulfovibrio alaskensis 6SR

Salmonella enterica serovar Typhimurium was expressed in Escherichia coli to overproduce hydrogen sulfide from thiosulfate for cadmium removal as cadmium sulfide (Bang et al. 2000). However, this task needs bacterial growth under anaerobic conditions, such that the hydrogen sulfide reacts with oxygen and the percentage of removal of cadmium is lower. The concentrations of cadmium removed by recombinant $E$. coli is 10 times lower than that of $D$. alaskensis 6SR. For this reason, SRB such as D. alskensis 6SR have a positive influence on the process called bioprecipitation for the removal of heavy metals, also this kind of mechanism allows for the easy recovery of metals by non-expensive physical methods. Besides, metal sulfides are also of interest as nanocrystals due to their special applications as semi-conductors, solar radiation absorbers, polymer surface coatings, cathode materials, solar cell components, electro-luminescent devices, and multilayer dielectric filters (Pan et al. 1997).

Moreover, industrial activities are the main sources of cadmium release to environment. This, increase the natural cadmium concentrations $(0.1-0.5 \mathrm{ppm}$ in earth's crust; 5 and $110 \mathrm{ng} / \mathrm{L}$ in ocean water) (Pacyna and Pacyna 2001). Major industrial sources of cadmium emissions include the mining of zinc, lead, copper and cadmium smelting; besides of the coal and oil-fired boiler; other urban and industrial emissions such as phosphate fertilizer manufacture; road dust and municipal and sewage sludge incinerators. These activities have registered the emission of cadmium highest in Asia with 1,176 tonnes and North America emitting 191 tonnes (Alloway and Steinnes 1999; Pacyna and Pacyna, 2001). In North America, the estimated emissions of cadmium from municipal waste and sewage sludge incineration were 8 and 7 tonnes/year, respectively. This fact, impact to environment in base to extension or volume of contaminated site and the order of magnitude of the cadmium concentration could be from 3 to $>300 \mathrm{mg} / \mathrm{kg}$ of soil, $\geq 11.8 \mathrm{mg} / \mathrm{mL}$ of waste water and $\geq 85 \mathrm{mg} / \mathrm{kg}$ of activity sludge (Alloway and Steinnes 1999). Then the using of bacteria sulfate reducing, particularity $D$. alaskensis $6 \mathrm{SR}$, can be an alternative in the removal and recuperation of cadmium from these environments, while other traditional physicochemical methods are not very efficient concentrations below $200 \mathrm{mg} / \mathrm{L}$ or the cost of treatment increases. Also, the strain has been tested on mixed metallic solutions with $\mathrm{Pb}^{2+}, \mathrm{Zn}^{2+}$ and $\mathrm{Cd}^{2+}$, and percentage of removal satisfactoriness. 


\section{Conclusion}

D. alaskensis $6 \mathrm{SR}$ is a sulfate-reducing bacterium with a great potential for metal removal processes from aqueous media. The tolerance for high cadmium concentration and the mechanistic steps followed by $D$. alaskensis $6 \mathrm{SR}$ for this metal's removal facilitate the removal and recovery of the metal by simple physical methods, without the need of cellular lysis or special washes. In addition, with this process the sulfide emission can be controlled.

Acknowledgments P.A.L.P. thanks CONACyT for the corresponding support via a graduate scholarship (CONACyT, No. 209840). The authors wish to express their sincere gratitude to the Center of Microscopy, Escuela Nacional de Ciencias Biológicas$I P N$, and to Dr. Miguel Meléndez Lira for his cooperation in the FT-IR analysis, Physics Department, CINVESTAV-IPN.

\section{References}

Aksu Z, Donmez G (2006) Binary biosorption of cadmium (II) and nickel (II) onto dried Chlorella vulgaris: co-ion effect on monocomponent isotherm parameters. Process Biochem 41:860-868

Alloway BJ, Steinnes E (1999) Anthropogenic additions of cadmium to soils. In: McLaughlin MJ, Singh BR (eds) Cadmium in soils and plants. Kluwer Academic Publishers, Dordrecht, pp 97-123

Arakaki A, Takeyama H, Tanaka T, Matsunaga T (2002) Cadmium recovery by a sulfate-reducing magnetotactic bacterium, Desulfovibrio magneticus RS-1, using magnetic separation. Appl Biochem Biotechnol 98-100:833-840

Arjoon A, Olaniran AO, Pillay B (2013) Co-contamination of water with chlorinated hydrocarbons and heavy metals: challenges and current bioremediation strategies. Int J Environ Sci Technol 10:395-412

Bang SW, Clark DS, Keasling JD (2000) Engineering hydrogen sulfide production and cadmium removal by expression of the thiosulfate reductase gene ( $p h s A B C$ ) from Salmonella enterica serovar Typhimurium in Escherichia coli. Appl Environ Microbiol 66:3939-3944

Beech IB, Cheung CWS (1995) Interactions of exopolymers produced by sulphate-reducing bacteria with metal ions. Int Biodeterior Biodegration 35:59-72

Braissant O, Decho W, Dupraz C, Glunk C, Przekop KM, Visscher PT (2007) Exopolymeric substances of sulfate-reducing bacteria: interactions with calcium at alkaline $\mathrm{pH}$ and implication for formation of carbonate minerals. Geobiology 5(4):401-411

Cabrera G, Pérez R, Gómez JM, Ábalos A, Cantero D (2006) Toxic effects of dissolved heavy metals on Desulfovibrio vulgaris and Desulfovibrio sp. strains. J Hazard Mater 135:40-46

Caffrey SM, Voordouw G (2009) Effect of sulfide on growth physiology and gene expression of Desulfovibrio vulgaris Hildenborough. Anton Leeuwenhoek 97:11-20

Cunningham DP, Lundie LL Jr (1993) Precipitation of cadmium by Clostridium thermoaceticum. Appl Environ Microbiol 59:7-14

Das N, Vimala R, Kartika P (2008) Biosorption of heavy metals-an overview. Indian J Biotechnol 7:159-169

Flemming HC, Wingender J (2001) Relevance of microbial extracellular polymeric substances (EPSs)-Part I: structural and ecological aspects. Water Sci Technol 43:1-8
Igwe JC, Abia AA (2006) A bioseparation process for removing heavy metals from waste water using biosorbents. Afr J Biotechnol 5:1167-1179

Jong T, Parry DL (2003) Removal of sulfate and heavy metals by sulfate reducing bacteria in short-term bench scale upflow anaerobic packed bed reactor runs. Water Res 37:3379-3389

Klonowska A, Clark ME, Thieman SB, Giles BJ, Wall JD, Fields MW (2008) Hexavalent chromium reduction in Desulfovibrio vulgaris Hildenborough causes transitory inhibition of sulfate reduction and cell growth. Appl Microbiol Biotechnol 78:1007-1016

Kolmert Å, Wikström P, Hallberg K (2000) A fast and simple turbidimetric method for the determination of sulfate in sulfatereducing bacterial cultures. J Microbiol Methods 41:179-184

Li QS, Wu G, Liu X, Liao X, Deng D, Sun Y, Hu Y, Huang Y (2004) Simultaneous biosorption of cadmium (II) and lead (II) ions by pretreated biomass of Phanerochaete chrysosporium. Sep Purif Technol 34:135-142

Muyzer G, Stams AJM (2008) The ecology and biotechnology of sulphate-reducing bacteria. Nat Rev 6:442-454

Naushad M, AL-Othman ZA, Islam M (2013) Adsorption of cadmium ion using a new composite cation exchanger polyaniline $\mathrm{Sn}(\mathrm{IV})$ silicate: kinetics, thermodynamic and isotherm studies. Int $\mathrm{J}$ Environ Sci Technol 10:567-578

Naz N, Young HK, Ahmed N, Gadd GM (2005) Cadmium accumulation and DNA homology with metal resistance genes in sulfate-reducing bacteria. Appl Microbiol Biotechnol 71:4610-4618

Neria-González I, Wang ET, Ramírez F, Romero JM, HernándezRodríguez C (2006) Characterization of bacterial community associated to biofilms of corroded oil pipelines from the Southeast of Mexico. Anaerobe 12:122-133

Odermatt A, Suter H, Krapf R, Solioz M (1993) Primary structure of two P-type ATPases involved in copper homeostasis in Enterococcus hirae. J Biol Chem 268:12775-12779

Ojeda JJ, Romero-Gonzalez ME, Pouran HM, Banwart SA (2008) In situ monitoring of the biofilm formation of Pseudomonas putida on hematite using flow-cell ATR FTIR spectroscopy to investigate the formation of inner-sphere bonds between the bacteria and the mineral. Mineral Mag 72:101-106

Pacyna JM, Pacyna EG (2001) An assessment of global and regional emissions of trace metals to the atmosphere from anthropogenic sources worldwide. Environ Rev 9:269-298

Pan ZY, Shen GJ, Zhang LG, Lu ZH, Liu JZ (1997) Preparation of oriented cadmium sulfide nanocrystals. J Mater Chem 7:531-535

Perry RD, Silver S (1982) Cadmium and manganese transport in Staphylococcus aureus membrane vesicles. J Bacteriol 150:973-976

Postgate JR (1981) Sulfate-reducing bacteria. Cambridge University Press, New York

Quintelas C, Rocha Z, Silva B, Fonseca B, Figueiredo H, Tavares T (2009) Biosorptive performance of an Escherichia coli biofilm supported on zeolite $\mathrm{NaY}$ for the removal of $\mathrm{Cr}(\mathrm{VI}), \mathrm{Cd}(\mathrm{II})$, $\mathrm{Fe}(\mathrm{III})$ and Ni(II). Chem Eng J 152:110-115

Syasina IG, Khlopova AV, Chukhlebova LM (2012) Heavy-metal and arsenic assessment of the state of the gibel carp carassius auratus gibelio in the Amur River Basin: heavy-metal and arsenic concentrations and histopathology of internal organs. Arch Environ Contam Toxicol 62:465-478

Utgikar VP, Harmon SM, Chaudhary N, Tabak HH, Govind R, Haines JR (2002) Inhibition of sulphate-reducing bacteria by metal sulfide formation in bioremediation of acid mine drainage. Environ Toxicol 17:40-48

Wang CL, Michels PC, Dawson SC, kitisakkul S, Baross JA, keasling JD, Clark DS (1997) Cadmium removal by a new strain of 
Pseudomonas aeruginosa in aerobic culture. Appl Environ Microbiol 63:4075-4078

You KM, Park YK (1998) $\mathrm{Cd}^{2+}$ removal by Azomonas agilis PY101, a cadmium accumulating strain in continuous aerobic culture. Biotechnol Lett 12:1157-1159

Zamani AA, Shokri R, Parizanganeh AH, Yaftian MR (2013)

Adsorption of lead, zinc and cadmium ions from contaminated water onto Peganum harmala seeds as biosorbent. Int J Environ Sci Technol 10:93-102

Zhang D, Wang J, Pan X (2006) Cadmium sorption by EPSs produced by anaerobic sludge under sulfate-reducing conditions. J Hazard Mater B138:589-593 